\title{
The relationship between fibromyalgia and pressure pain threshold in patients with dyspareunia
}

\author{
Hasan Terzi MD¹, Rabia Terzi MD², Ahmet Kale MD
}

\begin{abstract}
H Terzi, R Terzi, A Kale. The relationship between fibromyalgia and pressure pain threshold in patients with dyspareunia. Pain Res Manag 2015;20(3):137-140.
\end{abstract}

OBJECTIVE: To evaluate the number of tender points, pressure pain threshold and presence of fibromyalgia among women with or without dyspareunia.

METHODS: The present cross-sectional study included 40 patients with dyspareunia and 30 healthy controls. The participants were asked if they had engaged in sexual intercourse during the previous four weeks, and dyspareunia was rated from 0 to 3 based on the Marinoff Dyspareunia Scale. A pressure algometer (dolorimeter) was used to measure the pressure pain threshold. Fibromyalgia was diagnosed based on the 1990 American College of Rheumatology criteria. The depression status of the participants was assessed using the Beck Depression Inventory.

RESULTS: No statistically significant difference was found with regard to age, body mass index, habits (alcohol use and smoking), educational status and occupational status between the two groups. Total myalgic score, total control score and tender point mean pain threshold were significantly lower in the group with dyspareunia. The number of tender points was significantly higher in patients with dyspareunia. The mean Beck Depression Inventory score was $14.7 \pm 8.4$ in the dyspareunia group compared with $11.2 \pm 7.1$ in the control group. Five $(12.5 \%)$ of the patients with dyspareunia were diagnosed with fibromyalgia, whereas no patients in the control group were diagnosed with fibromyalgia. There was no significant difference between the two groups with regard to the presence of fibromyalgia.

CONCLUSION: The finding of lower pressure pain thresholds and a higher number of tender points among patients with dyspareunia suggests that these patients may have increased generalized pain thresholds. Additional studies involving a larger number of patients are required to investigate the presence of central mechanisms in the pathogenesis of dyspareunia.

Key Words: Depression; Dyspareunia; Fibromyalgia; Pressure pain threshold

Cibromyalgia syndrome is a rheumatic disorder characterized by widespread musculoskeletal pain, morning stiffness, fatigue and the presence of multiple tender points in the body. The prevalence has been reported to be $1.7 \%$ in the general population. This condition predominantly affects women, with a female:male ratio of 13.7:1 (1). Fibromyalgia syndrome causes a significant decrease in functional capacity and represents a barrier to maintaining daily activities of life by interfering with the social functioning of an individual (2). Fibromyalgia is frequently comorbid with other conditions, such as irritable bowel syndrome, dysmenorrhea, temporomandibular joint disorders, chronic fatigue syndrome, migraine, restless leg syndrome and affective disorders, all of which are believed to be involved in central sensitization (3-5).

Dyspareunia is defined by the American College of Obstetricians and Gynecologists as genital pain experienced immediately before, during or after sexual intercourse (6). Dyspareunia is categorized as superficial and deep. Pain during sexual intercourse can be felt around

\section{Le lien entre la fibromyalgie et le seuil de douleur à la pression chez des patientes ayant une dyspareunie}

OBJECTIF : Évaluer le nombre de points sensibles, le seuil de douleur à la pression et la présence de fibromyalgie chez des femmes ayant ou non une dyspareunie.

MÉTHODOLOGIE : La présente étude transversale incluait 40 patientes ayant une dyspareunie et 30 sujets en santé. Les chercheurs ont demandé aux participantes si elles avaient eu des relations sexuelles au cours des quatre semaines précédentes et de classer leur dyspareunie entre 0 et 3 selon l'échelle de dyspareunie de Marinoff. Un algomètre de pression (dolorimètre) a permis de mesurer le seuil de douleur à la pression. La fibromyalgie a été diagnostiquée selon les critères de l'American College of Rheumatology de 1990. L'état dépressif des participantes a été évalué au moyen de l'inventaire de dépression de Beck. RÉSULTATS : Les chercheurs n'ont constaté aucune différence significative sur le plan de l'âge, de l'indice de masse corporelle, des habitudes (consommation d'alcool et tabagisme), du niveau de scolarité et de la situation professionnelle entre les deux groupes. Le score myalgique total, le score témoin total et le seuil de douleur moyen aux points sensibles étaient considérablement plus faibles dans le groupe ayant une dyspareunie. Le nombre de points sensibles était significativement plus élevé chez les patientes ayant une dyspareunie. Le score moyen de l'inventaire de dépression de Beck s'élevait à 14,7 $\pm 8,4$ dans le groupe ayant une dyspareunie, par rapport à 11,2 $\pm 7,1$ dans le groupe témoin. Une fibromyalgie a été diagnostiquée chez cinq patientes ayant une dyspareunie (12,5\%), mais chez aucun patient du groupe témoin. Il n'y avait pas de différence significative entre les deux groupes quant à la présence de fibromyalgie.

CONCLUSION : D'après l'observation des seuils moins élevés de douleur à la pression et du plus grand nombre de points sensibles chez les patientes ayant une dyspareunie, ces patientes ont peut-être plus de seuils de douleur généralement élevés. Il faudra réaliser d'autres études auprès d'un grand nombre de patientes pour déterminer la présence de mécanismes centraux dans la pathogenèse de la dyspareunie.

the vagina and in the pelvic region (7). The prevalence of dyspareunia is reported to range from $8 \%$ to $21 \%$ (8). Acute somatic pain developing in association with dyspareunia is considered to induce peripheral sensitization, which, in turn, causes neuropathic pain through central sensitization (9). Provoked vestibulodynia is one of the most common causes of dyspareunia in women. An increase in the number of painful spots in patients with vulvar vestibulitis (10) and hyperactivity in the same brain areas on stimulation with pressure in patients with vulvodynia and fibromyalgia have suggested a possible relationship between dyspareunia and fibromyalgia (11).

The aim of the present study was to evaluate women with or without dyspareunia in terms of the number of tender points, pressure pain threshold and presence of fibromyalgia.

\section{METHODS}

The Institutional Review Board of Kocaeli University Faculty of Medicine (Kocaeli, Turkey) approved the study protocol. The study

${ }^{1}$ Department of Obstetrics and Gynecology; ${ }^{2}$ Department of Physical Medicine and Rehabilitation, Kocaeli Derince Education and Research

Hospital, Kocaeli, Turkey

Correspondence: Dr Rabia Terzi, Department of Physical Medicine and Rehabilitation, Kocaeli Derince Education and Research Hospital, Kocaeli,

Turkey. Telephone 90-262-317-80-64, e-mail drrabia1@yahoo.com 
TABLE 1

Comparison of groups with or without dyspareunia

\begin{tabular}{|c|c|c|c|}
\hline & $\begin{array}{l}\text { Dyspareunia } \\
(n=40)\end{array}$ & $\begin{array}{c}\text { Control group } \\
(n=30)\end{array}$ & $\mathbf{P}$ \\
\hline Age, years & $38.7 \pm 3.2$ & $39.2 \pm 4.1$ & 0.5 \\
\hline Body mass index, $\mathrm{kg} / \mathrm{m}^{2}$ & $27.5 \pm 5.2$ & $28.3 \pm 4.01$ & 0.6 \\
\hline Current smoker, n (\%) & $29(50)$ & $14(47)$ & 0.1 \\
\hline \multicolumn{4}{|l|}{ Education level, n (\%) } \\
\hline Elementary school & $10(25)$ & $7(23.3)$ & 0.6 \\
\hline High school & $15(37.5)$ & $12(40)$ & \\
\hline University & $15(37.5)$ & $11(36.7)$ & \\
\hline \multicolumn{4}{|l|}{ Employment, n (\%) } \\
\hline Housewife & $20(50)$ & $16(53.3)$ & 0.1 \\
\hline Employed & $20(50)$ & $14(46.7)$ & \\
\hline Beck Depression Inventory score & $14.7 \pm 8.4$ & $11.2 \pm 7.1$ & 0.1 \\
\hline Total myalgic score, $\mathrm{g} / \mathrm{cm}^{2}$ & $133.2 \pm 18.6$ & $164.2 \pm 9.2$ & $0.02^{\star}$ \\
\hline Total control score, $\mathrm{g} / \mathrm{cm}^{2}$ & $22.4 \pm 3.7$ & $27.5 \pm 3.4$ & $0.03^{*}$ \\
\hline Tender point count & $4.7 \pm 3.5$ & $1.5 \pm 1.1$ & $0.01^{*}$ \\
\hline Tender point mean pain threshold & $2.8 \pm 0.54$ & $3.9 \pm 1.0$ & $0.03^{\star}$ \\
\hline
\end{tabular}

Data presented as mean $\pm S D$ unless otherwise indicated. *Statistically significant $(P<0.05)$

participants were selected among patients who were admitted to the gynecology clinic. Patients who were admitted to the gynecology clinic were questioned by the same gynecologist for the presence of dyspareunia. The present cross-sectional study involved 40 patients with dyspareunia and 30 healthy controls. Women between 18 and 45 years of age who were sexually active and had a partner were included. Women with a known disease that could cause dyspareunia and those with a history of gynecological surgery, a major medical or psychotic disorder, and pregnant women were excluded from the study. A detailed medical history was obtained, and all patients underwent a physical examination. The demographic data, habits (alcohol use and smoking), medications and gynecological history were recorded for all patients. All participants were evaluated for depression, pressure pain threshold and fibromyalgia. The diagnosis of fibromyalgia was established by 1990 American College of Rheumatology (12) diagnostic criteria.

\section{Diagnosis of dyspareunia}

Participants were asked whether they had engaged in sexual intercourse during the previous four weeks and dyspareunia was rated on a four-point scale, ranging from 0 to 3 , using the Marinoff Dyspareunia Scale (13): 0 = no dyspareunia; 1 = causes discomfort, but does not interfere with the frequency of intercourse; $2=$ sometimes prevents intercourse; and 3 = completely prevents intercourse.

The severity of dyspareunia was assessed using a visual analogue scale (VAS), with 0 indicating no pain and 10 indicating severe pain.

\section{Pressure pain threshold}

A pressure algometer (dolorimeter; Baseline FDK, Fabrication Enterprises, USA) was used to measure pressure pain threshold. The algometer used in the present study consisted of a metal probe with a round rubber disc $(1 \mathrm{~cm}$ diameter) at one end; the probe was attached to a scale that can measure pressure in kilograms and pounds. The operator can apply pressure to the desired muscle by holding the scale. The pressure applied by pressing the rubber disc to the skin perpendicularly moves the needle in the scale clockwise through the metal probe. For pressure pain measurement in the present study, 18 bilateral tender points (insertion of the suboccipital muscle, upper midpoint of the trapezius muscle, origin of the supraspinatus muscle, lower part of the sternocleidomastoid muscle, second costochondral junction, $2 \mathrm{~cm}$ distal to the lateral epicondyle, upper lateral part of the gluteal region, surface of the greater trochanter and the medial fat pad of the knee) described in the 1990 American College of Rheumatology criteria for fibromyalgia (12), and four generally accepted control points used in many previous studies (thumb, nail, and volar side of the forearm bilaterally) (14) were used.

All tender points were marked. The palpation and dolorimetric measurements were performed by the same physician. The 18 tender points were palpated with approximately $4 \mathrm{~kg} / \mathrm{cm}^{2}$ of pressure with the thumb (just enough to blanch the examiner's thumb) and painful points were recorded. The total number of painful points was calculated for each patient.

Using the pressure algometer, pressure was applied on the 18 paired tender points and four control points. The pressure was increased by $1 \mathrm{~kg} / \mathrm{s}$, and the first pressure value that the patient perceived pain was recorded in $\mathrm{kg} / \mathrm{cm}^{2}$ units. The sum of painful pressures in kilograms (tender points) was recorded as the myalgic score, and the sum of painful pressures in kilograms in the four control points was recorded as the control point score. The mean tender point pressure pain threshold was calculated by dividing the sum of minimal pressure that induced pain during dolorimetric measurement in the tender points to the number of painful points.

\section{Depression}

The depression status of the patients was assessed via the Beck Depression Inventory. The Beck Depression Inventory is a self-reported depression scale with 21 items. The scores range from 0 to 63; higher scores indicate more severe depression. The scores were evaluated as follows: 0 to $13=$ no depression, 14 to $24=$ mild depression and $>25=$ severe depression (15).

\section{Statistical analysis}

Data were reported as mean \pm SD. The parametric data of the patients were compared through a $t$ test and the nonparametric data were compared through a $\chi^{2}$ test. The level of statistical significance was set at $\mathrm{P}<0.05$.

\section{RESULTS}

The mean $( \pm \mathrm{SD})$ age of the patients with dyspareunia included in the study was $38.7 \pm 3.2$ years, and the mean age of the control group was $39.2 \pm 4.1$ years. No statistically significant differences were observed with regard to age, body mass index, habits, educational status and occupational status between the two groups $(\mathrm{P}>0.05)$ (Table 1$)$.

The mean duration of dyspareunia was $16.3 \pm 5.1$ months. Dyspareunia was identified as grade 1 in 12 patients, grade 2 in 12 patients and grade 3 in 16 patients. Total myalgic score, total control score and tender point mean pain threshold were significantly lower in the group with dyspareunia. The tender point count was significantly higher in the group with dyspareunia. The Beck Depression Inventory score was $14.7 \pm 8.4$ in the dyspareunia group compared with $11.2 \pm 7.1$ in the control group. The difference was not statistically significant (Table 1).

Five $(12.5 \%)$ of the patients with dyspareunia were diagnosed with fibromyalgia, whereas no patients in the control group were diagnosed with fibromyalgia. The diagnosis of fibromyalgia was established in the presence of widespread body pain for $\geq 3$ months (right and left side of the body, below and above the waist, and axial pain) and presence of tenderness during palpation on $\geq 11$ of 18 tender points with approximately $4 \mathrm{~kg}$ pressure (just enough to blanch the nail of the thumb). There was no significant difference between the two groups in terms of the presence of fibromyalgia $(\mathrm{P}=0.09)$.

The mean age of the group with dyspareunia and fibromyalgia was $38.9 \pm 2.1$ years, compared with $38.7 \pm 2.3$ years in the group with dyspareunia but without fibromyalgia. The difference between the groups in terms of age was not statistically significant $(\mathrm{P}=0.14)$. The mean Beck Depression Inventory score was $18.1 \pm 6.7$ in the dyspareunia group with fibromyalgia compared with $11.3 \pm 4.1$ in the dyspareunia group without fibromyalgia. The difference was statistically significant $(\mathrm{P}=0.03)$. There was no significant difference between the groups with regard to dyspareunia grade $(P=0.2)$. The mean dyspareunia VAS score was $6.02 \pm 2.1$ in patients with fibromyalgia and $4.12 \pm 1.1$ in patients without fibromyalgia. There was a significant difference in dyspareunia VAS scores between the two groups $(\mathrm{P}=0.04)$ (Table 2). 


\section{DISCUSSION}

In the present study, pressure pain threshold was lower at the tender and control points in the patients with dyspareunia, and fibromyalgia was identified at a higher rate in these patients. The depression scores were significantly higher in patients with dyspareunia diagnosed with fibromyalgia compared with patients with dyspareunia without fibromyalgia.

Studies reported in the literature indicate that patients with dyspareunia are more sensitive to pain and tactile stimuli in the genital area $(10,16)$, and there are structural and functional abnormalities in the peripheral sensory nerves, especially in the vestibular and vulvar tissues (17). The peripheral sensitization in some patients is considered to induce a central sensitization over time (18). Thus, pain sensitivity in some patients may generalize to nongenital parts of the body $(16,19)$. Provoked vestibulodynia characterized by chronic and painful inflammation of vestibular structures is one of the most common causes of dyspareunia (20).

Pukall et al (21) evaluated 16 vulvar vestibulitis patients with genital pain and 16 control women in terms of generalized pain sensitivity. The tender points used to diagnose fibromyalgia were used in the evaluation. More tender points were identified in women with vulvar vestibulitis compared with the control group. Furthermore, these patients also described a considerably higher level of pain and discomfort. Thus, the results of this study indicate that the development of vulvar vestibulitis may involve mechanisms that are not limited to the genitals, and that these mechanisms may have more a centralized nature (21). In a study conducted by Granot et al (22), heat pain was administered to the forearms of patients to determine thresholds for pain and discomfort, and to also assess the perceived level of pain and discomfort associated with suprathreshold stimuli. This study demonstrated lower thresholds for pain and discomfort among vulvar vestibulitis patients, as well as a suprathreshold for perceived pain and discomfort that was 13 times greater than that of the controls (22). In the present study, the pressure pain threshold at tender and control points was lower in patients with dyspareunia than it was in patients in the control group, as is the case in fibromyalgia. This finding suggests that pain sensitivity may not be solely limited to the genital area in these patients; some central mechanisms may be involved in its etiology and there are diffuse interactions in pain modulation. There are a few morphological and functional studies that have investigated the brain with the hypothesis that central mechanisms may be involved in dyspareunia. In vulvar vestibulitis patients with genital pain, activation was identified on functional brain magnetic resonance imaging at the central pain centre, which was similar to conditions with chronic pain such as fibromyalgia, irritable bowel syndrome and chronic low back pain (23). In studies that used brain imaging techniques to investigate pain in patients with vulvodynia, the density of grey matter increased in the brain areas associated with

\section{REFERENCES}

1. Jones GT, Atzeni F, Beasley M, Flüß E, Sarzi-Puttini P, Macfarlane GJ. The prevalence of fibromyalgia in the general population - a comparison of the American College of Rheumatology 1990, 2010 and modified 2010 classification criteria. Arthritis Rheumatol 2015;67:568-75.

2. Tüzün EH, Albayrak G, Eker L, Sözay S, Daflkapan A. A comparison study of quality of life in women with fibromyalgia and myofascial pain syndrome. Disabil Rehabil 2004;26:198-202.

3. Orellana C, Casado E, Masip M, Galisteo C, Gratacós J, Larrosa M. Sexual dysfunction in fibromyalgia patients. Clin Exp Rheumatol 2008;26:663-6.

4. Aydin G, Başar MM, Keleş I, Ergün G, Orkun S, Batislam E. Relationship between sexual dysfunction and psychiatric status in premenopausal women with fibromyalgia. Urology 2006;67:156-61.

5. Yunus MB. Fibromyalgia and overlapping disorders: The unifying concept of central sensitivity syndromes. Semin Arthritis Rheum 2007;36:339-56.

6. American College of Obstetrics and Gynecology. Technical Bulletin no. 211. Washington, DC: ACOG; 1995. Sexual Dysfunction
TABLE 2

Grade of dyspareunia and pain scores according to the presence of fibromyalgia in patients with dyspareunia

\begin{tabular}{lccc}
\hline & \multicolumn{3}{c}{ Dyspareunia } \\
\cline { 2 - 3 } Variable & $\begin{array}{c}\text { + Fibromyalgia } \\
(\mathbf{n}=5)\end{array}$ & $\begin{array}{c}- \text { Fibromyalgia } \\
(\mathbf{n}=\mathbf{3 5})\end{array}$ & $\mathbf{P}$ \\
\hline Age, years, mean \pm SD & $38.9 \pm 2.1$ & $38.7 \pm 2.3$ & 0.1 \\
Marinoff Dyspareunia Scale & & & \\
Grade 1 & $1(20)$ & $11(31.4)$ & 0.2 \\
Grade 2 & $2(40)$ & $10(28.6)$ & \\
Grade 3 & $2(40)$ & $14(40)$ & \\
Visual analogue scale & $6.02 \pm 2.1$ & $4.12 \pm 1.1$ & $0.04^{*}$ \\
score, mean \pm SD & & & \\
\hline
\end{tabular}

Data presented as $n$ (\%) unless otherwise indicated. *Statistically significant $(P<0.05) .+$ With; - Without

pain modulation and stress (24). The presence of some central mechanisms in dyspareunia that are similar to some of the central mechanisms in fibromyalgia supports the coexistence of these two conditions.

Depression scores were significantly higher in the dyspareunia patients diagnosed with fibromyalgia. Studies in the literature have reported a positive correlation between the painful conditions and the severity of pain and depression (25). Similarly, the co-occurrence of two painful conditions - fibromyalgia and dyspareunia - may have led to higher depression scores in the present study.

In the present study, the presence of dyspareunia was assessed only in the previous four weeks. One study limitation was that patients who avoided frequent sexual intercourse due to dyspareunia were not evaluated in this group of patients. Furthermore, pressure pain threshold in the vulvar region was not evaluated. Further studies are required in this regard. Other limitations of the present study include the small patient population, and lack of electrophysiological and brain imaging studies, which provide more objective data about the presence of central mechanisms.

\section{CONCLUSION}

The pressure pain threshold was lower in patients with dyspareunia compared with the control group. The prevalence of fibromyalgia was analyzed in patients with dyspareunia. Patients with dyspareunia and fibromyalgia should be examined for depression. Additional studies involving a greater number of patients are required to investigate the presence of central mechanisms in the pathogenesis of dyspareunia.

DISCLOSURES: The authors have no conflicts of interest to declare.

FUNDING: The authors did not receive financial support for this study.

7. Butcher J. A psychosexual approach to managing dyspareunia. Practitioner 2003;247:484-9.

8. MacNeill C. Dyspareunia. Obstet Gynecol Clin N Am 2006;33:565-77.

9. Sadownik LA. Etiology, diagnosis, and clinical management of vulvodynia. Int J Womens Health 2014;6:437-49.

10. Pukall CF, Binik YM, Khalifé S, Amsel R, Abbott FV. Vestibular tactile and pain thresholds in women with vulvar vestibulitis syndrome. Pain 2002;96:163-75.

11. Hampson JP, Reed BD, Clauw DJ, et al. Augmented central pain processing in vulvodynia. J Pain 2013;14:579-89.

12. Wolfe F, Smythe HA, Yunus MB, Bennet RM, Bombardier C, Goldenberg DL. The American College of Rheumatology 1990 criteria for the classification of fibromyalgia. Report of the multicenter criteria committee. Arthritis Rheum 1990;33:160-72.

13. Marinoff SC, Turner ML. Vulvar vestibulitis syndrome. Dermatol Clin 1992;10:435-44.

14. Erdem HR, Çakıt BD, Çetinkaya E, Karagöz A, Saraçoğlu M. Evaluation of pain pressure threshold and frequency of fibromyalgia in patients with dysmenorrhea. Rheumatism 2007;22:11-4. 
15. Bumberry W, Oliver JM, McClure JN. Validation of the Beck Depression Inventory in a university population using psychiatric estimate as the criterion. J Consult Clin Psychol 1978;46:150-5.

16. Pukall CF, Young RA, Roberts MJ, Sutton KS, Smith KB. The vulvalgesiometer as a device to measure genital pressure-pain threshold. Physiol Meas 2007;28:1543-50.

17. Bohm-Starke N. Vulvar vestibulitis syndrome - Pathophysiology of the vestibular mucosa. Scand J Sexology 2001;4:227-34.

18. Sadownik LA. Etiology, diagnosis, and clinical management of vulvodynia. Int J Womens Health 2014;6:437-49.

19. Giesecke J, Reed BD, Haefner HK, Giesecke T, Clauw DJ, Gracely RH. Quantitative sensory testing in vulvodynia patients and increased peripheral pressure pain sensitivity. Obstet Gynecol 2004;104:126-33.

20. Heim LJ. Evaluation and differential diagnosis of dyspareunia. Am Fam Physician 2001;63:1535-45.
21. Pukall CF, Baron M, Amsel R, Khalifé S, Binik YM. Tender point examination in women with vulvar vestibulitis syndrome. Clin J Pain 2006;22:601-9.

22. Granot M, Friedman M, Yarnitsky D, Zimmer EZ. Enhancement of the perception of systemic pain in women with vulvar vestibulitis. BJOG 2002;109:863-6.

23. Pukall CF, Strigo IA, Binik YM, Amsel R, Khalife S, Bushnell MC. Neural correlates of painful genital touch in women with vulvar vestibulitis syndrome. Pain 2005;115:118-27.

24. Schweinhardt P, Kuchinad A, Pukall CF, Bushnell MC. Increased gray matter density in young women with chronicvulvar pain. Pain 2008;140:411-9.

25. Yap AU, Chua EK, Dworkin SF, Tan HH, Tan KB. Multiple pains and psychosocial functioning/psychologic distress in TMD patients. Int J Prosthodont 2002;15:461-6. 


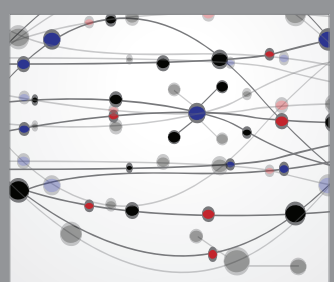

The Scientific World Journal
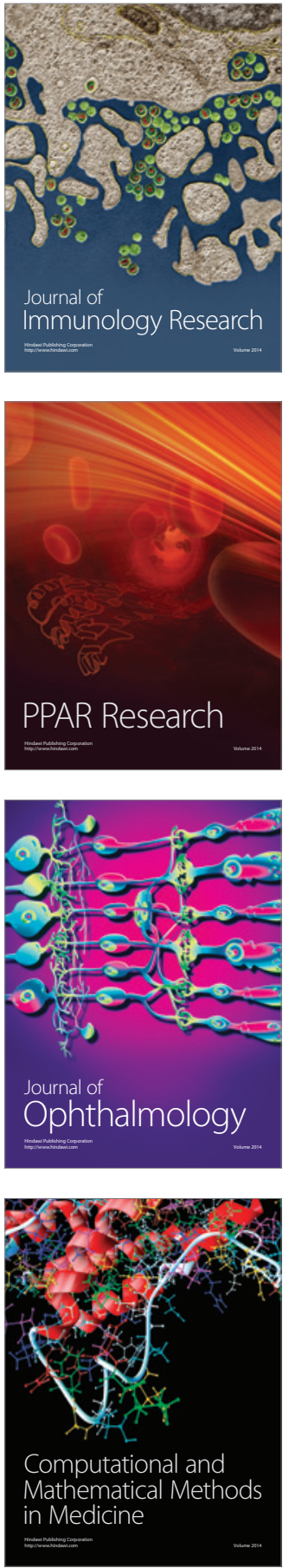

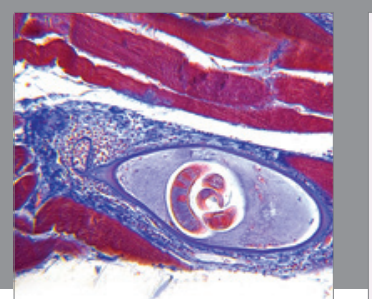

Gastroenterology Research and Practice

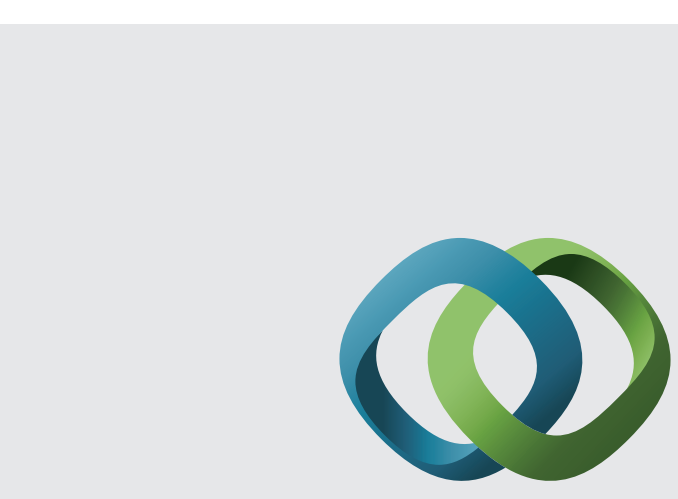

\section{Hindawi}

Submit your manuscripts at

http://www.hindawi.com
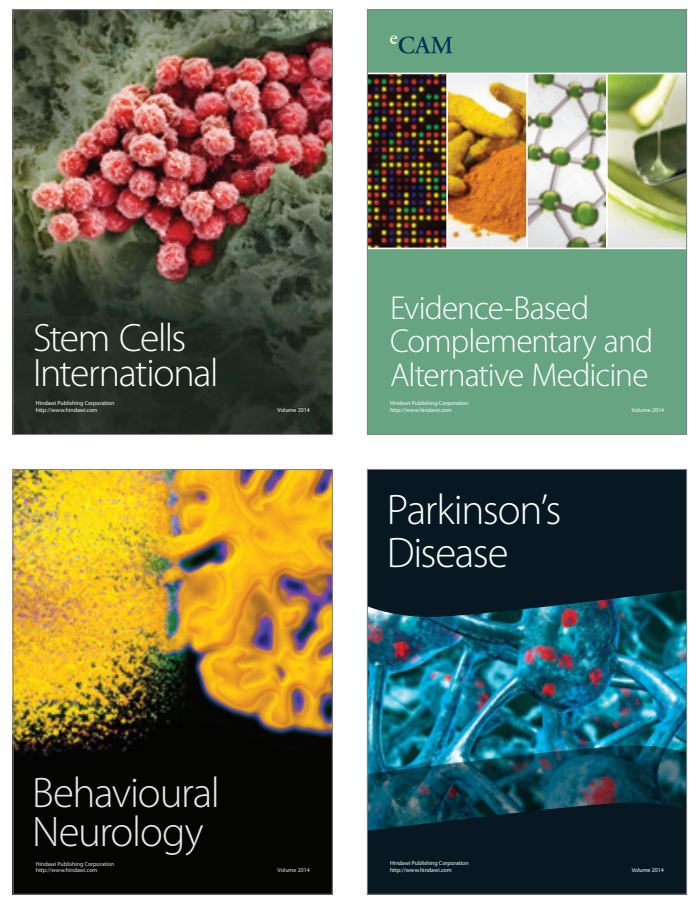
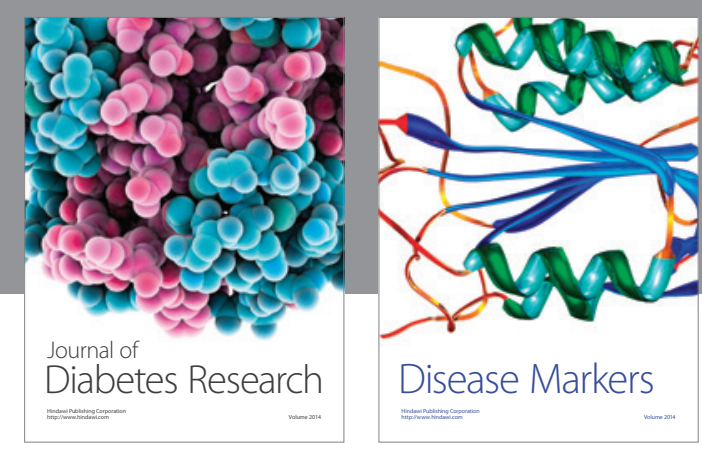

Disease Markers
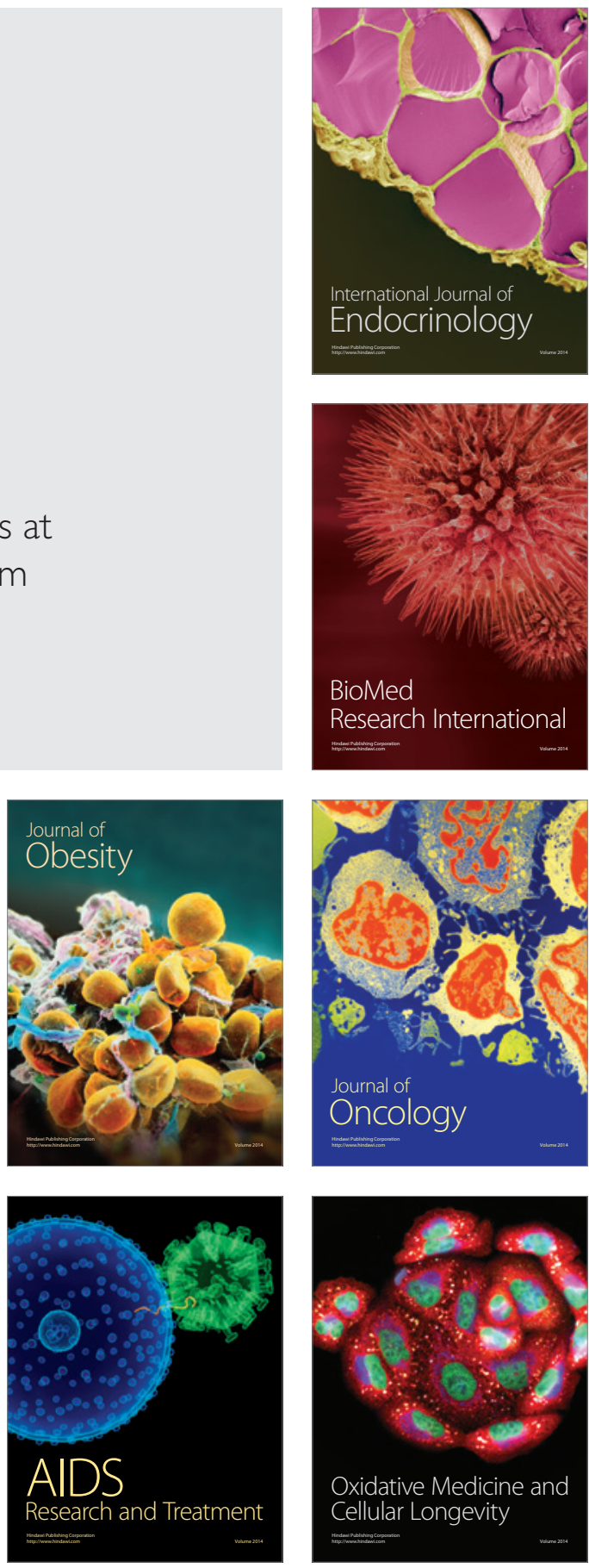